\title{
De la Licenciatura al Grado en Administración y Dirección de Empresas: un análisis comparativo desde las necesidades de las empresas
}

From the five years management Spanish degree to the four years bachelor's management degree: a comparative analysis from the firms' necessities point of view

Haydeé Calderón García (haydee.calderon@uv.es)

Trinidad Casasús Estellés (trinidad.casasus@uv.es)

Juan Francisco Martínez (juan.f.martinez@uv.es)

Universidad de Valencia (España)

http://dx.doi.org/10.12795/EDUCADE.2013.104.05

\begin{abstract}
RESUMEN: El proceso de Bolonia supone un cambio en la filosofía y la estructura de los planes de estudio de las universidades europeas y, consecuentemente, una oportunidad para que éstas revisen sus contenidos y superen errores. Partimos de la idea de que, según estudios analizados, los empleadores y egresados de las universidades españolas detectaban carencias significativas en las enseñanzas de la licenciatura en Administración y Dirección de Empresas (LADE). Planteamos que para las universidades españolas, la elaboración del grado en ADE (GADE) ha sido un desafío que permitía acercar los contenidos del título a la realidad empresarial. Por ello, el presente análisis tiene como finalidad constatar si el resultado de la transformación de LADE en GADE refleja un mayor acercamiento del título universitario a la demanda social y empresarial. Para conseguir el objetivo planteado se analizan y comparan los contenidos académicos de los planes de estudio de la licenciatura y del grado en ADE de las 12 mayores universidades españolas. Los resultados nos muestran que, en general en todas las universidades, los planes de estudio del grado se han centrado más en las materias propias de la economía de la empresa, exceptuando la Contabilidad, rebajando la participación de materias de contexto de la empresa y, también, de las materias de corte instrumental. Pero se aprecian también diferencias importantes entre las universidades analizadas en la composición de los planes de estudio. Se observa asimismo que la adaptación a las demandas de las empresas ha sido cubierta tan sólo parcialmente.
\end{abstract}

PALABRAS CLAVE: Materia de enseñanza, Administración y Dirección de Empresas, Convergencia Europea, universidades, empresas

\begin{abstract}
The Bologna Process involves a significant change in the philosophy and structure of the European university curricula, as well as an opportunity for these universities to review their syllabus and to improve their errors and lacks. At this paper we start from the idea that, following the analysed studies, the Spanish university employers and graduates detected significant shortages in the Management Studies five years Degree. We suggest that, for the Spanish universities, the development of a new four years curriculum degree in Management has been a challenge that allowed the universities to bring the syllabus of the degree closer to the managerial reality. That is why the goal of this paper is to state whether the transformation of the five years to the fourth year's degree has also meant a higher rapprochement of the university studies to the social and managerial demand.
\end{abstract}

Artículo de investigación. Recibido: 15-01-13 - Versión revisada: 16-04-13, 30-04-13, Aceptado: 28-05-13

Licencia Creative Commons BY NC ND · 2013 · Asociación Española de Contabilidad y Administración de Empresas - AECA 
To that end we will analyse and compare the academic syllabus of both five years and new four years degree in Management Studies of the twelve biggest Spanish universities. The results show no great differences in the actions of those universities. On the whole, the curricula of the four years degree are focused in specific subjects of business economies, except Accounting, decreasing the hours of subjects dedicated to the firm's context and subjects with an instrumental character. But, there also exists important differences between the universities analysed in the composition of the curriculum. We also observe that the adaptation to the demands of the firms has been only partial.

KEYWORDS: University education, Management, European Convergence, Bologna Process, Firms, EEES.

\section{INTRODUCCIÓN}

El proceso de Convergencia Europea de la Enseñanza Superior comenzó con la Declaración de Bolonia, firmada el 19 de junio de 1999 por 30 estados europeos, con el objetivo de armonizar el diseño del Espacio Europeo de Educación Superior (EEES).

El 24 de marzo de 2000, el Consejo Europeo reunido en Lisboa acordó un nuevo objetivo estratégico para la Unión: "desarrollar el conocimiento más competitivo y dinámico del mundo, capaz de un crecimiento económico sostenible, con más y mejores empleos y mayor cohesión social a fin de reforzar el empleo, la reforma económica y la cohesión social como parte de una economía basada en el conocimiento". La modificación de las enseñanzas universitarias europeas y la unificación de las calificaciones favorecería este objetivo, por la mejor formación, la mejora de la competitividad de las personas y por la mayor movilidad laboral (Wende, 2000)'.

A partir de ese momento, en los países de la UE se inició un proceso de sintonización y transformación de los estudios superiores que permitió profundizar en un proceso de Convergencia Europea y que se dio por finalizado en 2010, año en el que se habían adherido más de 40 países a la iniciativa.

A este contexto de cambio impulsado por las instituciones se le suma un entorno marcado por la crisis económica y financiera y las consecuentes políticas de ajuste realizadas en todos los sectores, pero de forma particular en el de la educación. Si a esto añadimos la profusión de publicaciones de rankings internacionales de universidades (Martínez, 2011), nos encontramos en la actualidad con el esfuerzo de las universidades por mejorar su competitividad (Plewa et al., 2008) y por ofrecer mayor valor a la sociedad en general y en concreto a estudiantes, graduados, instituciones y empresas.

De acuerdo con Froment (2003), los principales agentes implicados con las universidades, estudiantes, empresas y gobiernos deben ejercer presión para que las reformas emprendidas cubran sus necesidades. En este sentido, el propio Real Decreto 1393/2007, que regula para España la ordenación de las enseñanzas universitarias

\footnotetext{
I Si bien es cierto que se plantea un Espacio Europeo de Educación Superior armonizado, de calidad y excelencia, referente mundial y abierto a todos los ciudadanos (Fidalgo y García, 2008), al mismo tiempo se hace necesario mantener la diversidad en términos de contenido para poder asegurar que se ajustan a las necesidades de los estudiantes de diferentes países europeos (Froment, 2003), e incluso de diferentes zonas en un mismo país.
} 
oficiales, establece, entre otros, la preocupación y orientación del sistema hacia la empleabilidad de los egresados, estableciendo en sus preliminares que "La nueva organización de las enseñanzas incrementará la empleabilidad de los titulados". Esta preocupación también está en los futuros empleadores que demandan información fiable sobre lo que significa una capacitación y un título determinado y que buscan que las universidades sean competitivas en la preparación del estudiante para el desarrollo de su labor profesional (Rodríguez, 2009).

En definitiva, entre los principales pilares de los nuevos títulos universitarios actuales se encuentran fomentar la empleabilidad y desarrollar un enfoque más aplicado de los estudios universitarios, más adecuado a lo que las empresas y la sociedad necesitan. En este sentido, cabe plantearse si los cambios producidos en los planes de estudio efectivamente consiguen cubrir la demanda del entorno empresarial, que será quién se nutra de los conocimientos y el saber hacer adquirido por los estudiantes en su período de formación universitaria.

Para ello, abordamos una investigación centrada en la titulación que tiene actualmente mayor demanda laboral (Segundo Estudio de OPAL, 2011), la titulación de Administración y Dirección de Empresas. Para destacar la importancia de los estudios de Licenciado en Administración y Dirección de Empresas (LADE) y Graduado en Administración y Dirección de Empresas (GADE), objeto de nuestro análisis, exponemos los siguientes datos: en la Universidad Española, en el curso 2004-2005 había 95.875 estudiantes matriculados en LADE (Fuente: Libro Blanco y Consejo de Coordinación Universitaria). El número de estudiantes matriculados en primer curso ascendió en toda España en el curso 2006- 2007 a 112.115 , lo que supuso un 3,21\% más que el curso anterior, y permitió cubrir el $95 \%$ de las plazas ofertadas en todo el territorio nacional (Fuente: CCU). En relación a los/las alumnos/as graduados/as, durante el curso 2003-2004 se licenciaron en ADE, un total de 10.886 estudiantes (Fuente: CCU). Del análisis de otras estadísticas elaboradas periódicamente por el CCU, la titulación en ADE es la más demandada por los/las estudiantes que desean cursar titulaciones del área de Ciencias Sociales y Jurídicas

El objetivo general de este trabajo es constatar si el resultado de la transformación de LADE en GADE refleja un mayor acercamiento del título universitario a la demanda social y empresarial. Este objetivo general se concreta a través de los siguientes objetivos específicos:

- Verificar las diferencias en el peso relativo de los conocimientos específicos básicos en LADE y GADE.

- Constatar las diferencias entre las universidades españolas analizadas.

- Comparar los resultados con la demanda de las empresas.

Para alcanzar dichos objetivos, hemos partido de la revisión bibliográfica de diferentes estudios (entre los que incluimos el Libro Blanco del título de Grado en Economía y Empresa), que valoran el nivel de convergencia o distanciamiento que perciben los empleadores entre los contenidos de LADE y la realidad empresarial. En segundo lugar, hemos analizado el contenido de los planes de estudios de la licenciatura y del grado en ADE de 12 universidades españolas con el fin de comprobar si los contenidos del grado puede disminuir las diferencias señaladas en los estudios analizados.

\section{ANTECEDENTES Y MARCO TEÓRICO}

El proceso de reforma universitaria plantea en España una profunda transformación de la enseñanza a nivel de modelo o conceptualización, estructura, organización o 
funcionamiento y gestión de las universidades, de acuerdo con las directrices en que se fundamenta el EEES (Fidalgo et al., 2007).

Hay que tener en cuenta que el punto de partida era complejo. El sistema universitario español ha estado sometido a una gran demanda social desde los años 80, por lo que ha visto cómo se multiplicaba el número de estudiantes que accedían a las universidades. De hecho, España se situó a la cabeza de Europa en cuanto alumnado universitario (Tejedor et al., 2007). La rapidez de este crecimiento dificultó que se pudiesen concebir estructuras y formas de organización adaptadas a la nueva situación.

En España, el proceso de transformación se inició con el Real Decreto 55/2005, de 21 de Enero, que regulaba los títulos de grado y postgrado y siguió con el Real Decreto 1393/2007, de 29 de Octubre, que estableció las directrices de elaboración de estos títulos. La restructuración, el reconocimiento de titulaciones y el sistema de reconocimiento de créditos (ECTS) han pasado por el diseño y elaboración de las diferentes titulaciones dentro de las universidades, universidades que de acuerdo con Girotto et al. (2013), cuentan con un control directo más débil del Estado, una gestión institucional más fuerte y una mayor autonomía institucional, aunque también están sometidas a una mayor rendición de cuentas. Así pues, tal y como afirman Fidalgo et al. (2007), la labor hacia la convergencia se ha desarrollado dentro de cada institución de enseñanza universitaria, tomando decisiones que han tenido que obviar intereses particulares, tradicionales o individualismos para dar respuesta a las nuevas demandas con una apertura al ámbito social y mundial. El resultado tiene una dimensión social que va mucho más allá del entorno puramente universitario y académico, afectando al conjunto de la sociedad y muy directamente al mercado laboral y a las empresas, que son, al fin y al cabo, el destino natural de la gran mayoría de titulados superiores (Martínez, 2009).

Efectivamente, la reforma en el sistema de enseñanza y aprendizaje no se centra exclusivamente en la estructura de los estudios, sino también, de forma significativa, en el currículo. El contenido de los planes de estudio ha tratado de prestar atención a las transformaciones económicas que están teniendo lugar en Europa (Rodríguez, 2009), a las necesidades sociales y al mercado de trabajo (Arquero et al., 2009). También ha intentando corregir el supuesto excesivo academicismo y otras cuestiones no bien tratadas, como la interdisciplinariedad en los estudios, el trabajo en equipo (Michavila, 2009) y el desarrollo de competencias técnicas, conductas, actitudes e intereses relativos al campo profesional (Oliveros, 2006). Los propios estudiantes perciben como elementos positivos de la reforma de los planes de estudio una mejor preparación de cara al futuro laboral, según los resultados de la investigación realizada por Masferrer (2010). Aunque debe señalarse que existe un amplio debate sobre si la educación que proporcionan las universidades para los estudiantes deben ser condicionadas a las necesidades del mercado de trabajo o si la educación que se imparte debe ser independiente de esas necesidades (Marzo et al., 2009). El estudio realizado por Mora et al. (2009), muestra cómo las empresas confirman que las universidades tienen que formar graduados que posean las competencias que les permitan llevar a cabo adecuadamente las funciones de los puestos de trabajo determinados, básicamente habilidades metodológicas. Las empresas del estudio detectan una brecha significante entre la educación universitaria y la formación requerida a los estudiantes.

LADE, al igual que la mayoría de las licenciaturas en España, ha pasado de tener un plan de estudios compuesto por 300 créditos divididos en cinco cursos académicos a estar estructurado en 240 créditos y cuatro cursos académicos.

Atendiendo a las directrices del BOE para LADE: Las enseñanzas conducentes a la obtención del título oficial de Licenciado en Administración y Dirección de Empresas 
deberán proporcionar una formación científica adecuada en los aspectos básicos y aplicados de la economía de la empresa, así como de la organización y dirección empresarial. Anexo I del Real Decreto 1421/1990 (B.O.E de 20 de Noviembre de 1990)

En cuanto al GADE su razón de ser es la siguiente: Formar profesionales capaces de desempeñar labores de gestión, asesoramiento y evaluación en las organizaciones productivas. Esas labores se pueden desarrollar en el ámbito global de la organización o en cualquiera de sus áreas funcionales: producción, recursos humanos, financiación, comercialización, inversión, administración o contabilidad. El graduado debe conocer la articulación del normal desenvolvimiento de todas estas áreas funcionales con los objetivos generales de la unidad productiva, de éstos con el contexto global de la economía y estar en condiciones de contribuir con su actividad al buen funcionamiento y a la mejora de resultados. En concreto, debe saber identificar y anticipar oportunidades, asignar recursos, organizar la información, seleccionar y motivar a las personas, tomar decisiones, alcanzar objetivos propuestos y evaluar resultados. (Libro Blanco del Título de Grado en Economía y Empresa, 2005)²

En esta primera aproximación a ambos títulos, ya se pueden apreciar diferencias significativas en cuanto a su filosofía de partida. Los objetivos establecidos para el grado concretan la visión de LADE, incorporando el desempeño de la gestión, el asesoramiento y la evaluación, frente a la anterior perspectiva más genérica de organización y dirección empresarial. Así mismo, el grado hace especial referencia a las áreas funcionales de la empresa. Esta somera visión de ambas definiciones nos acerca a una primera idea de que GADE, al menos en su idea de partida, se acerca más a la realidad empresarial.

Se han publicado diversos estudios en los que se refleja el grado de adaptación de los estudios de LADE a las necesidades de la empresa y/o la sociedad, y que presentamos en el Cuadro 1. Son estudios e informes realizados entre 2005 y 2010 con el objetivo de aportar información que serviría de punto de partida en el diseño de GADE. En todos ellos la muestra está compuesta por empleadores de egresados de LADE y/o por egresados que están desarrollando una labor profesional.

El Libro Blanco del título de grado en Economía y Empresa (ANECA, 2005) se elaboró con el objetivo de tener información útil para la elaboración de los planes de estudios de los nuevos grados en el área de la economía y la empresa. El estudio se fundamentó en encuestas realizadas a profesionales, profesores, egresados y empleadores. Si bien, tal y como se reconoce en el mismo Libro Blanco, la muestra no es representativa, se permite vislumbrar algunos aspectos destacables. La cuestión que más interesa a los efectos del presente trabajo, en la que nos vamos a centrar, es la que hace referencia a los conocimientos específicos más importantes de los estudios de empresa, concretamente, en la titulación de LADE. Tal y como observamos en el Cuadro 2, las respuestas entre los colectivos profesionales, empleadores y egresados fueron coincidentes. Los conocimientos básicos más valorados fueron: Contabilidad Financiera, Contabilidad de Costes, Dirección Financiera, Análisis de Inversiones Financieras y Organización y Administración de Empresas. Los conocimientos peor valorados fueron: Historia Económica, Econometría e Investigación Comercial.

\footnotetext{
2 Ante la falta de una definición oficial del Grado en ADE tomamos como referencia la definición del Libro Blanco del Título en Economía y Empresa.
} 
Cuadro 1. Recopilación de ESTUdios SObRe ADAPTACIÓn LADE - Demanda social

\begin{tabular}{|c|c|c|c|c|}
\hline Autor/Organismo & $\begin{array}{c}\text { Año } \\
\text { del } \\
\text { estudio }\end{array}$ & Muestra & $\begin{array}{l}\text { Materias más } \\
\text { relevantes para el } \\
\text { ejercicio de la } \\
\text { profesión }\end{array}$ & $\begin{array}{l}\text { Materias menos } \\
\text { relevantes para el } \\
\text { ejercicio de la profesión }\end{array}$ \\
\hline $\begin{array}{l}\text { Libro Blanco } \\
\text { ANECA (2005) }\end{array}$ & 2005 & $\begin{array}{l}\text { Egresados } \\
\text { Empleadores } \\
\text { Profesionales } \\
\text { Profesores }\end{array}$ & $\begin{array}{l}\text { Contabilidad } \\
\text { financiera } \\
\text { Análisis de } \\
\text { Inversiones } \\
\text { Contabilidad de } \\
\text { Costes } \\
\text { Dirección Financiera } \\
\text { Organización y } \\
\text { Administración de } \\
\text { Empresas }\end{array}$ & $\begin{array}{l}\text { Historia Económica } \\
\text { Econometría } \\
\text { Investigación Comercial }\end{array}$ \\
\hline $\begin{array}{l}\text { Organización de } \\
\text { Economistas de } \\
\text { la Educación. } \\
\text { Marín et al. } \\
(2008) \\
\text { Marín et al. } \\
(2009)\end{array}$ & $\begin{array}{l}2008 \\
2009\end{array}$ & Egresados & $\begin{array}{l}\text { Contabilidad } \\
\text { Finanzas } \\
\text { Derecho } \\
\text { Marketing } \\
\text { Estrategia } \\
\text { Recursos Humanos } \\
\text { Idiomas }\end{array}$ & $\begin{array}{l}\text { Economía del Sector } \\
\text { Público } \\
\text { Sociología } \\
\text { Historia Económica } \\
\text { Econometría }\end{array}$ \\
\hline Martinez et al. & 2010 & Empleadores & $\begin{array}{l}\text { Capacidades } \\
\text { Genéricas } \\
\text { orientadas al trabajo } \\
\text { en una Organización }\end{array}$ & $\begin{array}{l}\text { Capacidades } \\
\text { Específicas que } \\
\text { responden a áreas } \\
\text { funcionales de la } \\
\text { empresa. }\end{array}$ \\
\hline Arguero et al. & 2009 & $\begin{array}{l}\text { Empleadores } \\
\text { Egresados }\end{array}$ & $\begin{array}{l}\text { Contabilidad } \\
\text { Idiomas } \\
\text { Informática } \\
\text { Fiscalidad } \\
\text { Finanzas }\end{array}$ & $\begin{array}{l}\text { Historia } \\
\text { Sociología } \\
\text { Teoría Económica } \\
\text { (Macro y Micro) }\end{array}$ \\
\hline $\begin{array}{l}\text { Unidad Calidad } \\
\text { Universidad } \\
\text { Alicante }\end{array}$ & 2010 & Empleadores & $\begin{array}{l}\text { Idiomas } \\
\text { Contabilidad } \\
\text { Dirección Financiera }\end{array}$ & \\
\hline
\end{tabular}

Fuente: Elaboración propia 
Cuadro 2. Clasificación de Conocimientos Específicos Básicos

\begin{tabular}{|c|c|}
\hline CONOCIMIENTO ESPECÍFICOS BÁSICOS & CLASIFICACIÓN \\
\hline Contabilidad Financiera & 1 \\
\hline Contabilidad de Costes & 2 \\
\hline Dirección Comercial & 8 \\
\hline Investigación Comercial & 16 \\
\hline Dirección Financiera & 3 \\
\hline Análisis de Inversiones Financieras & 4 \\
\hline Economía Financiera Internacional & 14 \\
\hline Organización y Administración de Empresas & 5 \\
\hline Microeconomía & 9 \\
\hline Macroeconomía & 13 \\
\hline Economía Española y Mundial & 15 \\
\hline Análisis Matemático & 10 \\
\hline Estadística & 7 \\
\hline Régimen Fiscal de la Empresa & 6 \\
\hline Derecho de la Empresa & 12 \\
\hline Historia Económica & 18 \\
\hline Econometría & 17 \\
\hline Matemáticas de las Operaciones Financieras & 11 \\
\hline
\end{tabular}

Fuente: Libro Blanco del título de grado en Economía y Empresa (ANECA, 2005)

Otros autores también analizan la relación entre los conocimientos que el estudiante obtiene en la Universidad al cursar LADE y lo que las empresas necesitan para que estos estudiantes, una vez egresados, se integren en sus estructuras empresariales. Así, por ejemplo, Martínez et al. (2010), de la Universidad Pontificia de Comillas, comparan el perfil de competencias profesionales que demandan los empleadores con las competencias que adquieren los estudiantes de la titulación de LADE. Entre las conclusiones destacamos el hecho de que los profesionales valoran que los estudios en LADE preparen a los estudiantes en competencias generales, es decir, en enseñanzas orientadas al trabajo en una organización, no siendo tan importante la formación en capacidades específicas, es decir, enseñanzas que respondan a las funciones de la empresa. 
En esta línea, un estudio realizado por la Unidad Técnica de Calidad de la Universidad de Alicante (2010) determina que, si bien la mayoría de los déficits formativos detectados por los empleadores hacen referencia no tanto a contenidos teóricos concretos, sino al aprendizaje de técnicas y herramientas para la inmersión en el mundo laboral, hay algunas carencias en cuanto a contenidos académicos se refiere. Los contenidos mejor valorados son el idioma, sobre todo inglés, y por otra parte, las carencias que se detectan pertenecen a las áreas de conocimiento de Contabilidad y Dirección Financiera.

Arquero et al. (2009) realizan un exhaustivo análisis sobre el perfil profesional demandado a los titulados en LADE. El estudio se centró en egresados en LADE de la Universidad de Sevilla. De los resultados obtenidos, destacamos que las materias más relevantes para el ejercicio de la profesión son, por orden de importancia, Contabilidad, Idiomas, Informática, Fiscalidad y Finanzas. Las menos valoradas fueron Historia, Sociología y Teoría Económica (Macroeconomía y Microeconomía).

Con un enfoque diferente, aunque complementario, la Organización de Economistas de la Educación (Marín et al., 2008), realizó un estudio sobre la percepción de los propios egresados sobre las competencias y habilidades adquiridas en sus estudios universitarios en el ámbito de la Economía y la Empresa. La valoración global es la existencia de un distanciamiento entre la realidad social y empresarial y las enseñanzas universitarias. De los resultados de dicha investigación se extrae que las materias que los egresados consideran muy importantes para el posterior desempeño de la actividad profesional son Contabilidad y Finanzas. Le siguen, en orden de importancia, Derecho, Marketing, Estrategia y Recursos Humanos. Las menos valoradas fueron Economía del Sector Público, Sociología, Historia Económica y Econometría. Además de la valoración de estas materias, puntúan a la baja la preparación de los estudios universitarios al mundo laboral. Entre las competencias que debería fomentar la titulación, destacan "organizar y planificar", "iniciativa" y "segundas lenguas" (Marín et al., 2009).

Del conjunto de los estudios presentados podemos concluir que las materias más destacadas por su utilidad en el ejercicio de la profesión y a las que se les debería dar más importancia en el plan de estudios son la Contabilidad, las Finanzas y la Organización y Administración de Empresas. Estas materias comprenden contenidos como la Contabilidad de Costes y Financiera, la Dirección Financiera, el Análisis de Inversiones, la Estrategia de Empresa, los Recursos Humanos, entre otras. Por otra parte, las materias que destacan como menos relevantes son la Historia Económica, la Sociología y Econometría. Vemos cómo, exceptuando el estudio de Martinez et al. (2010) basado en competencias, se destacan las áreas funcionales de la empresa, específicamente dos de ellas, la Contable y la Financiera, y como es obvio, la de Organización y Gestión Empresarial. Los idiomas se repiten en los estudios como un área importante a trabajar.

\section{METODOLOGÍA}

\subsection{MUESTRA}

Para llevar a cabo la selección de las universidades españolas cuyos planes de estudio vamos a analizar, hemos tomado como único criterio el número de plazas que se ofrecen en GADE. De esta forma, pretendemos conseguir una muestra lo suficientemente significativa en cuanto al número de estudiantes que presumiblemente se titularán con estos nuevos planes de estudio. Por otra parte, el centrarnos en titulaciones con muchos estudiantes permite presuponer un claustro de profesorado más amplio y variado, que podría llevarnos a una mayor flexibilidad en el 
proceso de elaboraciones de planes de estudio y, a su vez, a una mayor posibilidad de adaptarse a los nuevos requerimientos del entorno universitario $y$, como consecuencia, mayor oportunidad de cambio.

Para ello, hemos hecho uso de la base de datos on-line de Universia (http://estudios.universia.net/espana), el buscador de estudios de la ANECA (http://srv.aneca.es/ListadoTitulos) y la base de datos de Consumer Eroski (http://universidades.consumer.es). Las tres bases de datos se estructuran como buscadores que permiten localizar la información básica sobre universidades y titulaciones españolas. La última aporta, además, el número de plazas ofertadas.

Conocido el conjunto de universidades que ofrecen GADE en el Sistema Universitario Español, seleccionamos para su estudio aquellas universidades cuyos grados ofrecían al menos 300 plazas de nuevo acceso. El total de estudiantes de GADE atendidos por estas universidades supone el $48,25 \%^{3}$ del total del alumnado en Administración y Dirección de Empresas en España.

A los planes de estudio se tuvo acceso a través de las páginas web de las Universidades seleccionadas. Cuando no estaban disponibles en dicha web, se accedió a la publicación del plan de estudios en el BOE.

Las universidades que forman parte del estudio aparecen en el Cuadro 3.

CuAdro 3. Universidades ANALIZADAS

\begin{tabular}{ll}
\hline UNIVERSIDADES & $\begin{array}{l}\text { Número de estudiantes de } \\
\text { ADE de nuevo ingreso }\end{array}$ \\
\hline Universitat de Barcelona & 1150 \\
\hline Universidad de Murcia & 588 \\
\hline Universidad de Sevilla & 513 \\
\hline Universidad Complutense de Madrid & 477 \\
\hline Universitat de Valencia & 440 \\
\hline Universidad de Málaga & 407 \\
\hline Universidad de Zaragoza & 400 \\
\hline Universidad del País Vasco & 370 \\
\hline Universidad Carlos III & 310 \\
\hline Universitat Ramón Llull & 300 \\
\hline Universidad de Santiago de Compostela & 300 \\
\hline Universidad Pública de Navarra & 300 \\
\hline Un &
\end{tabular}

Fuente: Elaboración propia

\footnotetext{
3 De acuerdo con los datos proporcionados por la base de datos Consumer-Eroski (consultada 19/09/2012).
} 


\subsection{Procedimiento}

Con cada uno de los planes de estudios de estas universidades se ha llevado a cabo un doble análisis. En primer lugar, se ha analizado el carácter de cada una de las asignaturas de los antiguos planes: Troncales, Obligatorias y Optativas; y de los nuevos planes: materias de Formación Básica, Obligatoria y Optativas. En segundo lugar, las asignaturas han sido clasificadas de acuerdo con los conocimientos específicos que contienen cada una de ellas. Para ello, se ha tomado como referencia el listado de Conocimientos Específicos Básicos del Libro Blanco del Título de Grado de Economía y Empresa que aparecen en el Cuadro 2 añadiéndole "Otros", "Prácticas en Empresa" y "Trabajo de fin de grado".

Para realizar esta segunda clasificación, se creó un grupo de expertos compuesto por profesores de distintas áreas de conocimiento, con experiencia en la elaboración de planes de estudio, que analizaron los programas de las asignaturas, identificando los Conocimientos Específicos Básicos que eran tratados en cada una, tanto de los nuevos planes como de las licenciaturas. La asignación al Conocimiento Básico correspondiente se realizó individualmente y, en caso de conflicto, era revisada en una reunión por el conjunto de profesores. De esta forma se ha configurado la base de datos utilizada en nuestro estudio empírico.

\section{RESULTADOS}

En el Gráfico 1 presentamos el porcentaje que representa la oferta de cada una de las universidades, respecto al total de los créditos ofertados por la suma de las universidades consideradas.

Gráfico 1. Comparación en términos Relativos de LA Oferta ECTS LADE-GADE

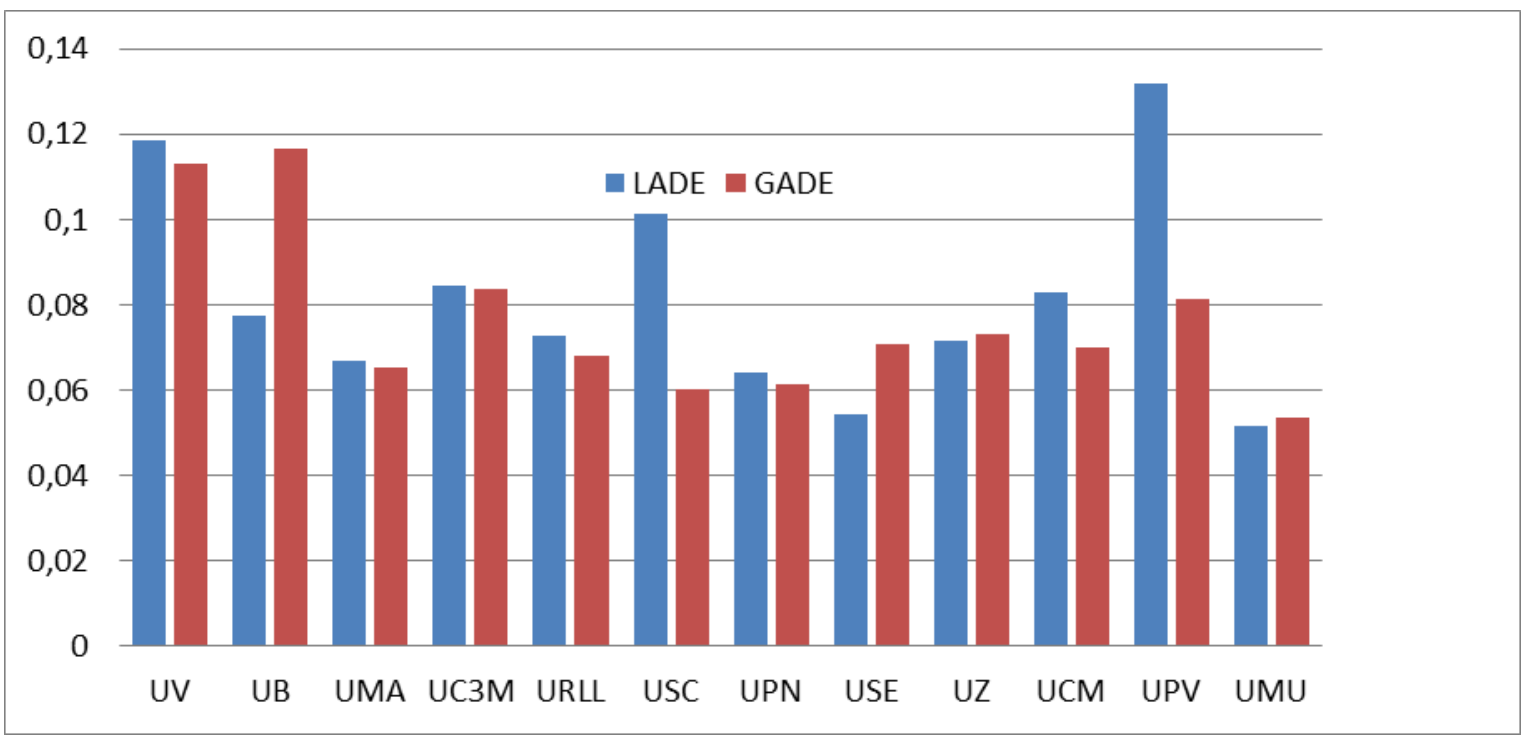

Fuente: Elaboración propia

Observamos cómo, con el cambio de titulaciones, se han producido algunas modificaciones significativas en el peso relativo de las universidades. Entre aquellas universidades que han incrementado su oferta de créditos en términos relativos respecto a la licenciatura destacan la Universidad de Barcelona y la Universidad de Sevilla. En el otro extremo están la Universidad de Santiago de Compostela, la Universidad Complutense de Madrid y la Universidad del País Vasco que han reducido su oferta; destacando la elevada reducción de oferta de la Universidad de Santiago 
de Compostela y la Universidad del País Vasco. El resto de universidades han tenido movimientos poco significativos.

Respecto a la carga docente distribuida en Materias Obligatorias, Optativas y Troncales, en los Gráficos 2 y 3 se refleja su distribución en LADE y en GADE para el conjunto de materias ofertadas por universidades.

GRÁFICO 2. DistribuCIÓN DE MATERIAS LADE

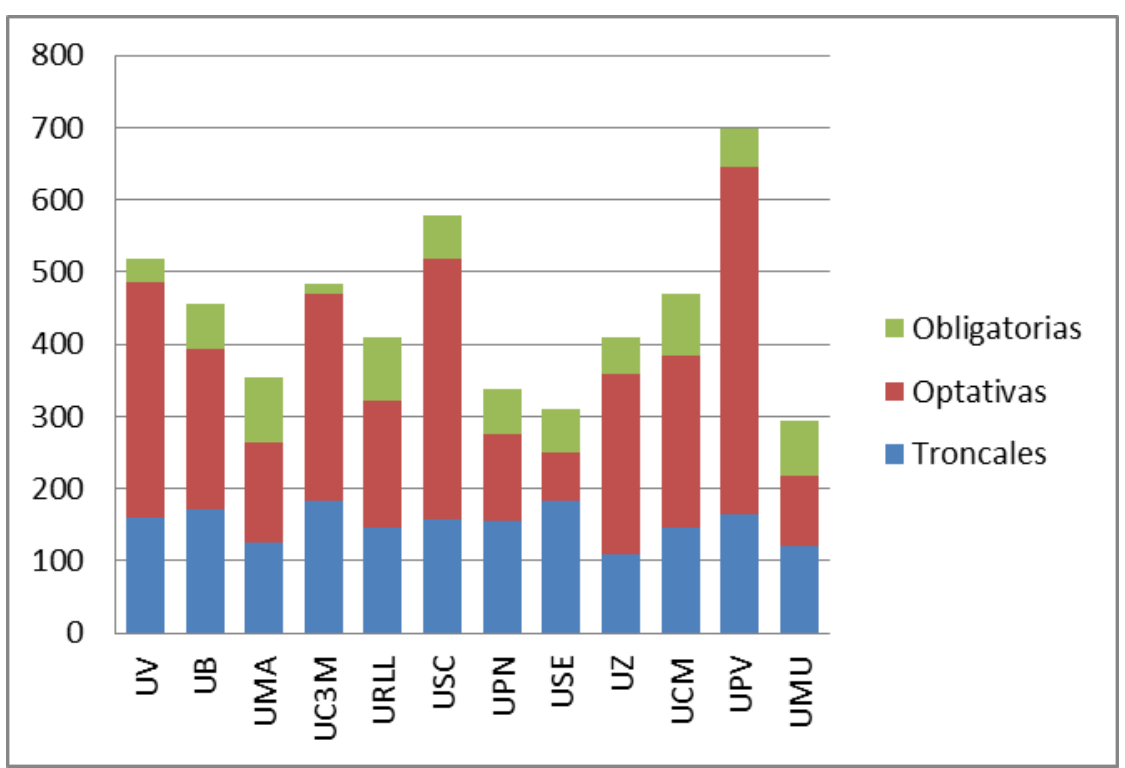

Fuente: Elaboración propia

GRÁfICo 3. DistribuCión DE MATERIAS GADE

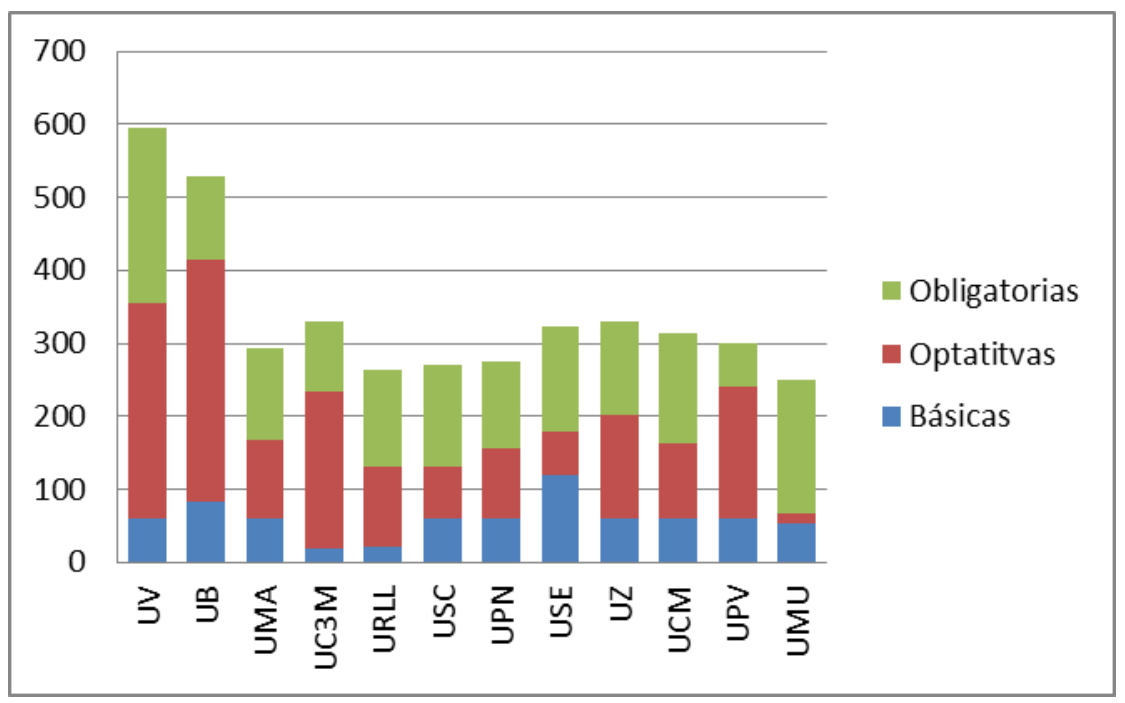

Fuente: Elaboración propia

En general todas las universidades disminuyen el peso de la optatividad, excepto la Universidad de Barcelona. Las reducciones más significativas se producen en las universidades de Santiago de Compostela y la Universidad de Murcia. La reducción del título a 4 años puede ser una explicación lógica a esta disminución, de hecho, en la licenciatura una parte importante de la optatividad se ofrecía en quinto curso. 
Asimismo, las universidades han intentado compensar este hecho ofreciendo un abanico más o menos amplio de postgrados oficiales especializados.

A continuación, comparamos los Conocimientos Específicos que se impartían en LADE con los que se imparten en GADE. Dado que la comparación en términos absolutos no sería válida debido a la diferencia de créditos, hemos realizado el cálculo en términos relativos. Para ello hemos calculado el porcentaje de créditos que supone cada uno de los Conocimientos Específicos, en el cómputo global de los créditos ofrecidos en esa titulación. En un primer momento lo hemos calculado de manera global para conocer el peso de cada Conocimiento Específico en el total de créditos ofertados por el conjunto de todas las universidades analizadas (Gráfico 4) y posteriormente hemos realizado el cálculo por universidades (Gráficos 5 y 6).

Gráfico 4. Comparativa Conocimientos Específico LADE-GADE

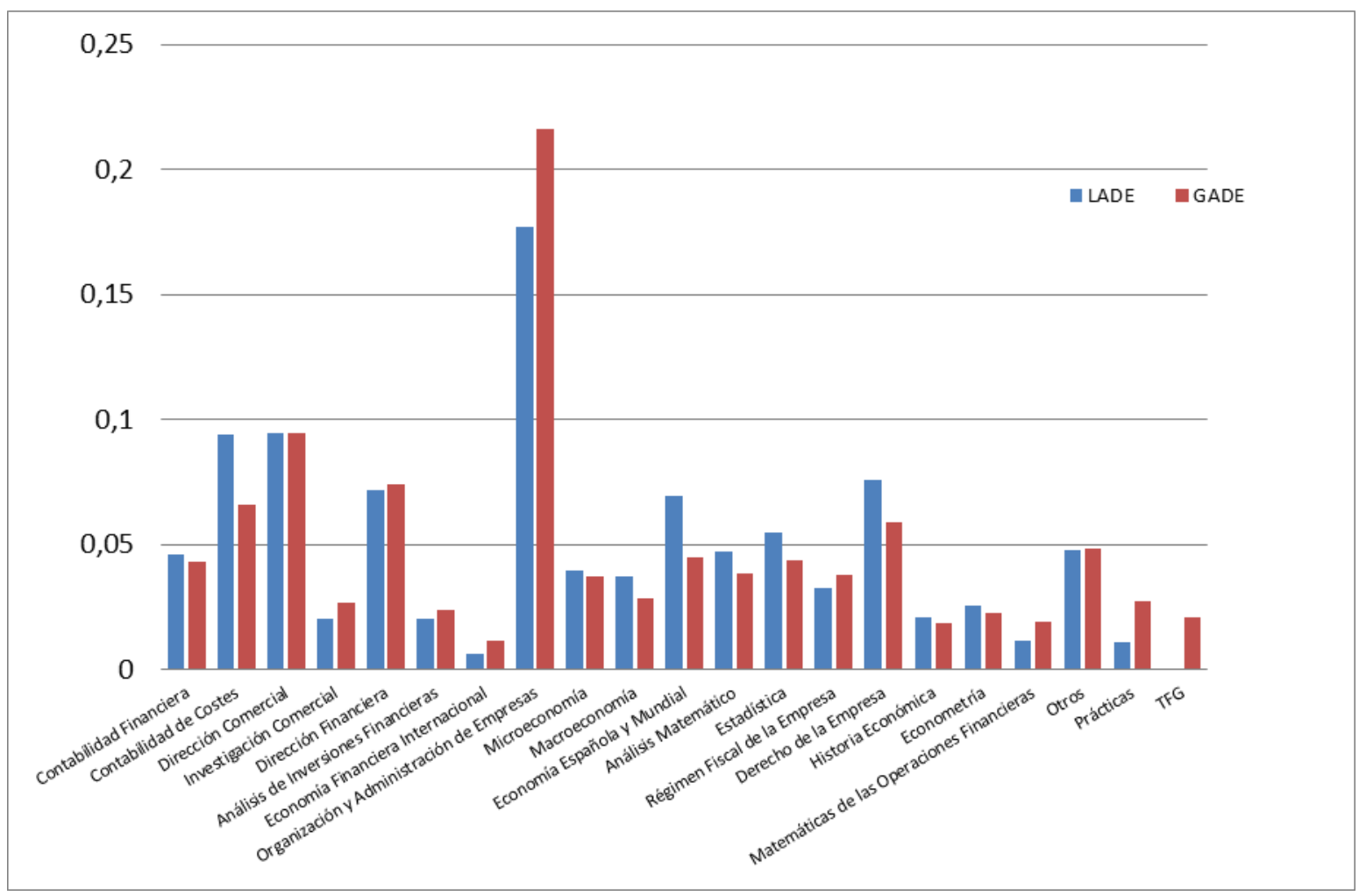

Fuente: Elaboración propia

El Gráfico 4 nos permite observar que, además de la aparición generalizada del Trabajo Final de Grado, el crecimiento más significativo para el conjunto de las universidades estudiadas se ha producido en Organización y Administración de Empresas y en las Prácticas en Empresa. Han incrementado su peso, aunque de forma menos destacada, la Investigación Comercial, la Dirección Financiera, el Análisis de Inversiones Financieras, la Economía Financiera Internacional, el Régimen Fiscal de la Empresa, y las Matemáticas de las Operaciones Financieras. Por otra parte se ha reducido la Contabilidad de Costes y el Derecho de la Empresa de manera destacada y, en menor medida, la Macroeconomía, el Análisis Matemático y la Estadística. Otros conocimientos específicos, como la Contabilidad Financiera, la Microeconomía, la Historia Económica o la Econometría han disminuido algo su importancia relativa pero de manera poco significativa. Es destacable que tanto la Historia como la Econometría, dos de los conocimientos específicos mencionados en 
mayor medida por los profesionales como los de menor utilidad, han sufrido una pequeña disminución de su carga relativa.

Si estudiamos los resultados por universidades (Gráficos 5 y 6) podemos observar el porcentaje de recursos que cada universidad ha dedicado a los distintos Conocimientos Específicos. La lectura de los mismos nos dan una visión general de qué Conocimientos Específicos se imparten con igual distribución (importancia) en todas las universidades y cuáles son impartidos solamente en algunas de ellas. Si bien cada uno de los Conocimientos Específicos muestran distinto peso en diferentes universidades, llama la atención, en el caso de la licenciatura, la poca generalización de materias del área de Economía Financiera Internacional, cuestión que no se ha modificado de forma significativa en los nuevos planes de estudio.

\section{GrÁfICO 5. Conocimientos ESPECífICOS LADE POR UNIVERSIDADES}

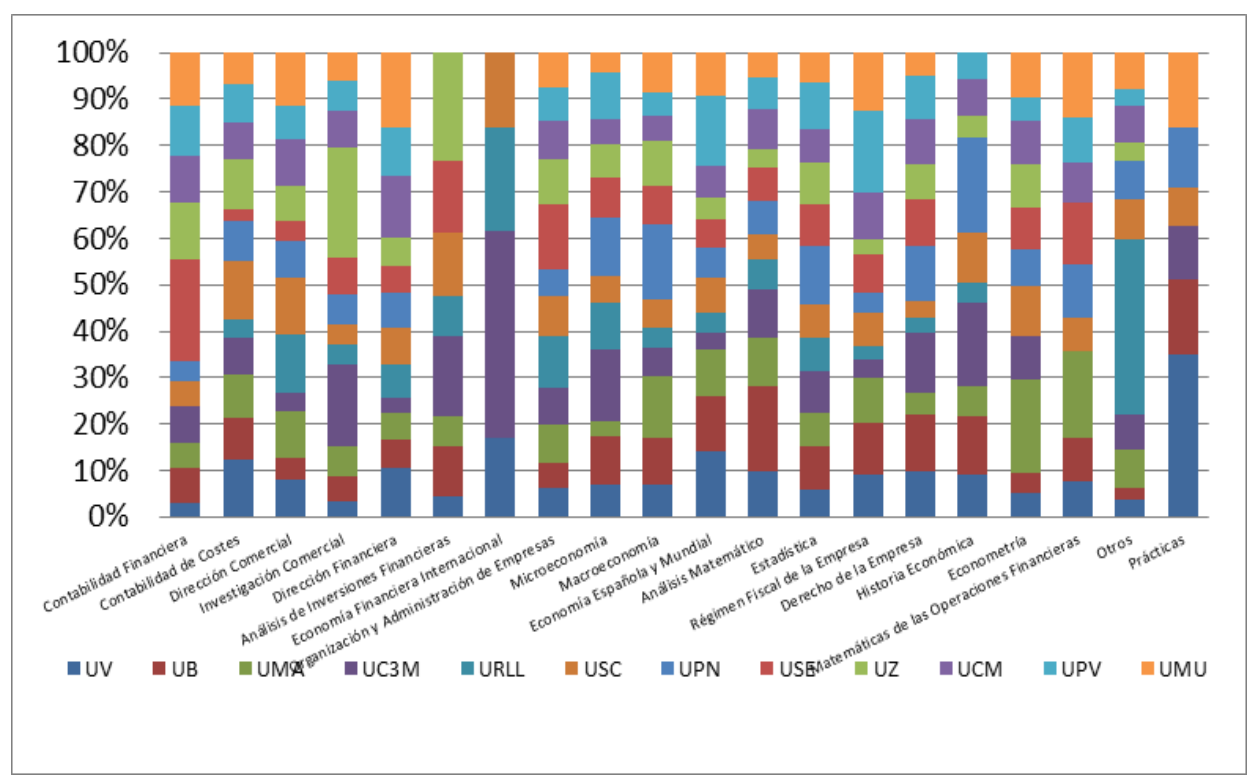

Fuente: Elaboración propia

GRÁFICO 6. CONOCIMIENTOS ESPECÍFICOS GADE POR UNIVERSIDADES

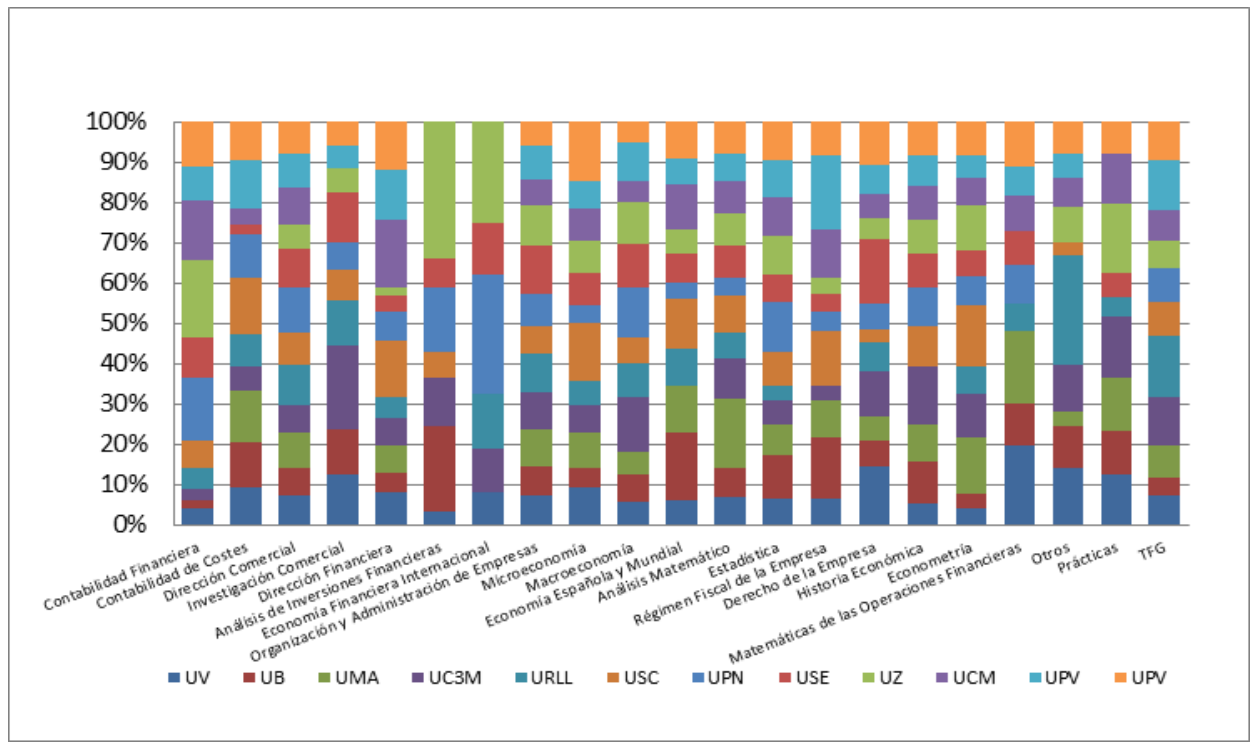

Fuente: Elaboración propia 
En el Gráfico 7 podemos comparar el peso de los Conocimientos Específicos en la Troncalidad y Obligatoriedad de LADE frente al peso en las Básicas y Obligatorias de GADE.

Gráfico 7. Comparativa de Troncales y Obligatorias (LADE) y Básicas y Obligatorias (GADE)

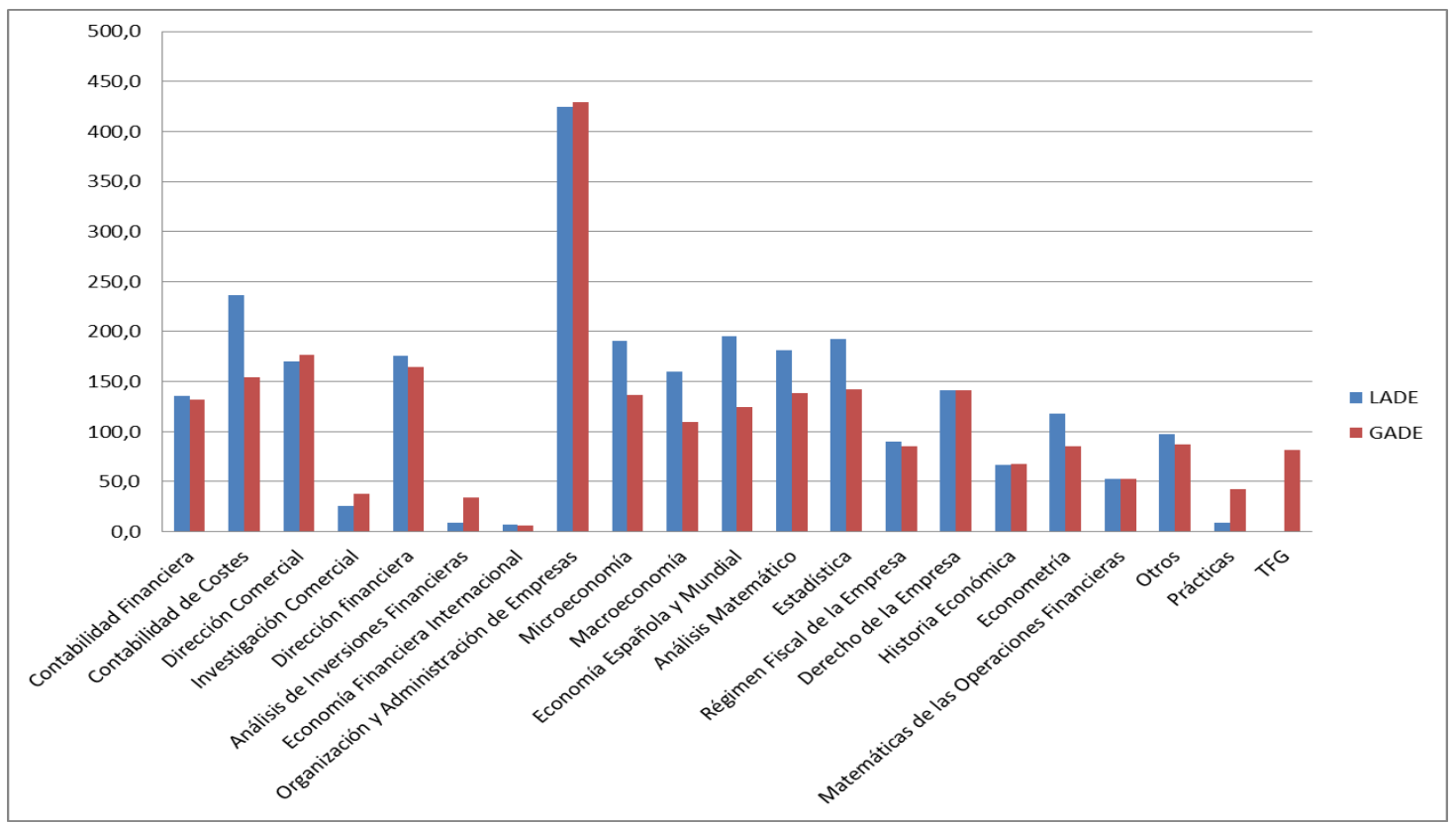

Fuente: Elaboración propia

De forma similar, el Gráfico 8 refleja el peso de los Conocimientos Específicos como Optativas en LADE y en GADE.

Gráfico 8. Comparativa de Optativas en LADE y Optativas en GADE

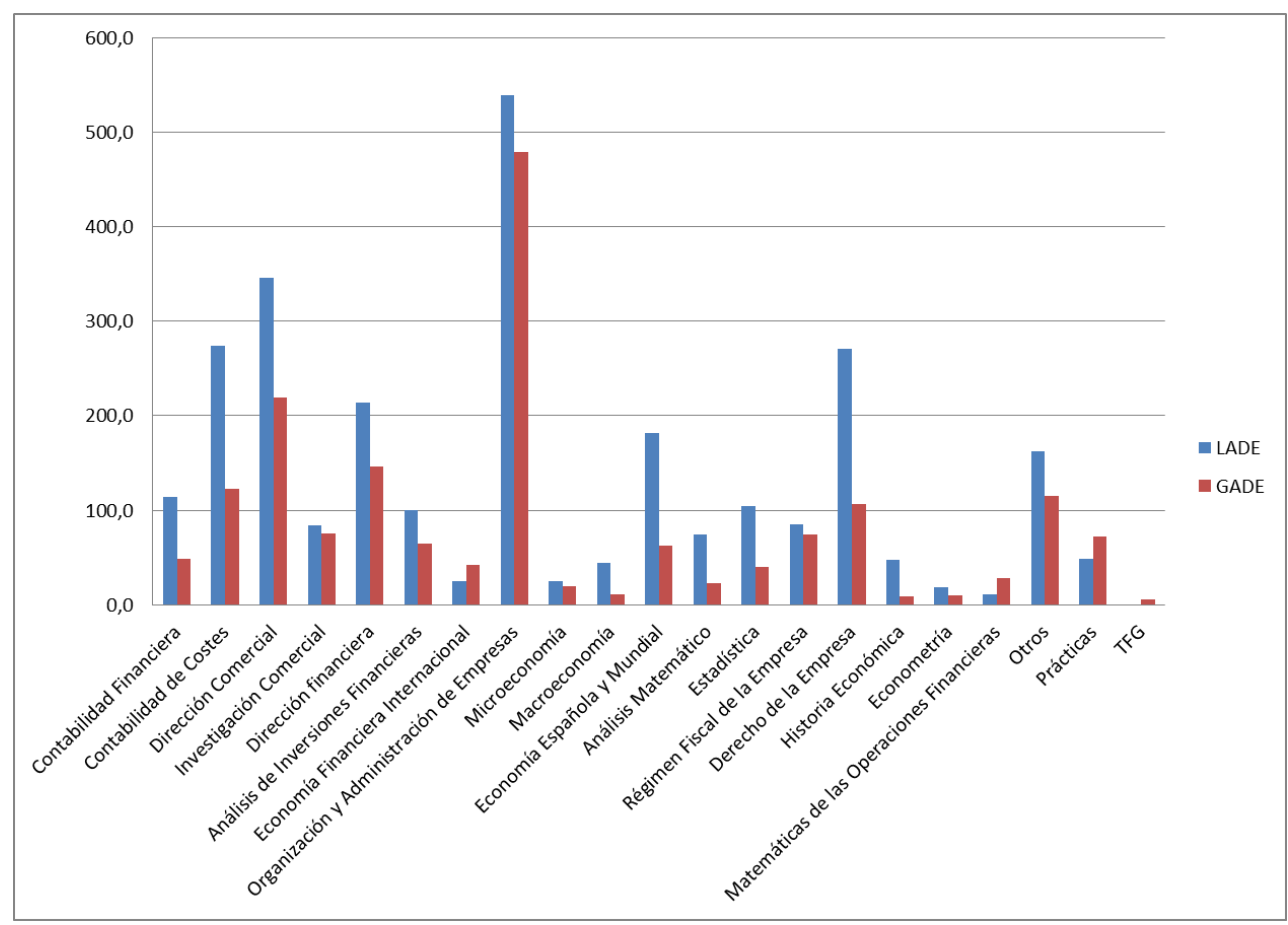

Fuente: Elaboración propia 
Observamos cómo algunos Conocimientos Específicos disminuyen de forma significativa su peso en la Troncalidad/Obligatoriedad, sobre todo aquellos que tienen que ver con el análisis del contexto de la dirección de empresas (la Macroeconomía, la Microeconomía, la Economía Española), al igual que algunos de los conocimientos más instrumentales (Análisis Matemático, Estadística o Econometría). También han visto rebajados sus pesos relativos algunas de las áreas directamente vinculadas con el conocimiento básico del título y la Economía de la Empresa, como son las Contabilidades (de forma más significativa la Contabilidad de Costes) y la Dirección Financiera. El aumento de peso en la obligatoriedad se concentra especialmente en la materia central del título, la Organización y Administración de Empresas y, en menor manera, en otros conocimientos de la Economía de la Empresa, como son el Marketing (Operativo y Estratégico) y el Análisis de Inversiones Financieras.

Para el caso de la Optatividad, excepto las Matemáticas de las Operaciones Financieras y la Economía Financiera Internacional, que muestran un ligero aumento, todos los Conocimientos Específicos han visto rebajada su participación. Sin embargo, nuevamente, destaca el número de créditos que mantiene Organización y Administración de Empresas (que tiene una reducción menor). Resulta llamativa la disminución en la Optatividad de los conocimientos de ambos tipos de Contabilidades (Financiera y de Costes), de Dirección Comercial y de Dirección Financiera. Nuevamente, son castigados conocimientos de contexto, como la Economía Española y Mundial y el Derecho de la Empresa y los conocimientos instrumentales como el Análisis Matemático y la Estadística.

En los Gráficos 9 y 10 se observa la distribución de ECTS por Conocimientos Específicos Obligatorios (hemos unido Obligatorios y Troncales) para LADE y para GADE, incluyendo las universidades responsables del título.

GRÁFICO 9. ECTS ObLIGATORIOS EN LADE POR UNIVERSIDADES Y CONOCIMIENTOS ESPECífICOS

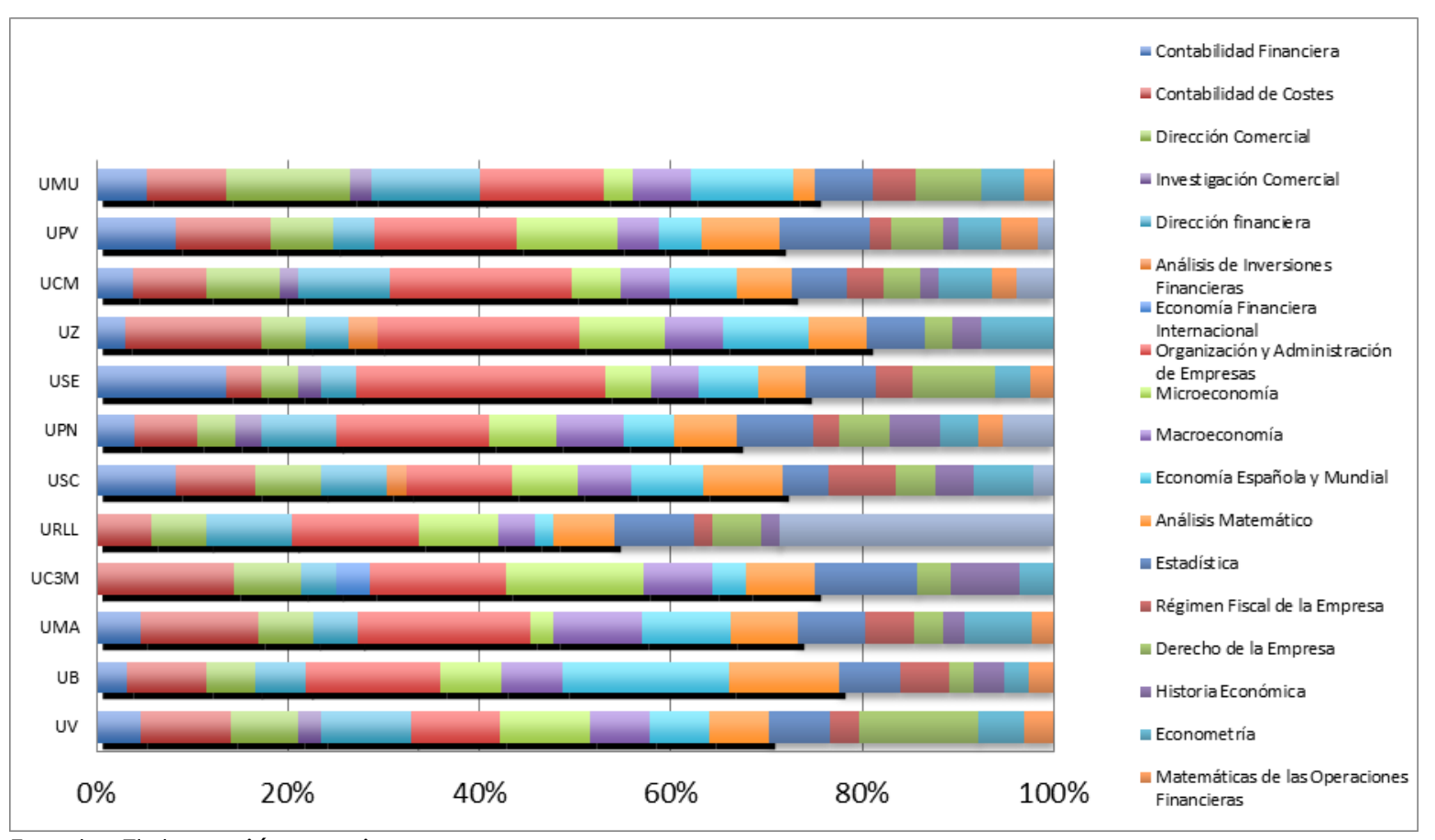

Fuente: Elaboración propia 
GRÁfico 10. ECTS ObligAtoRIOS EN GADE POR UNIVERSIDADES y CoNOCIMIENTOS ESPECíficos

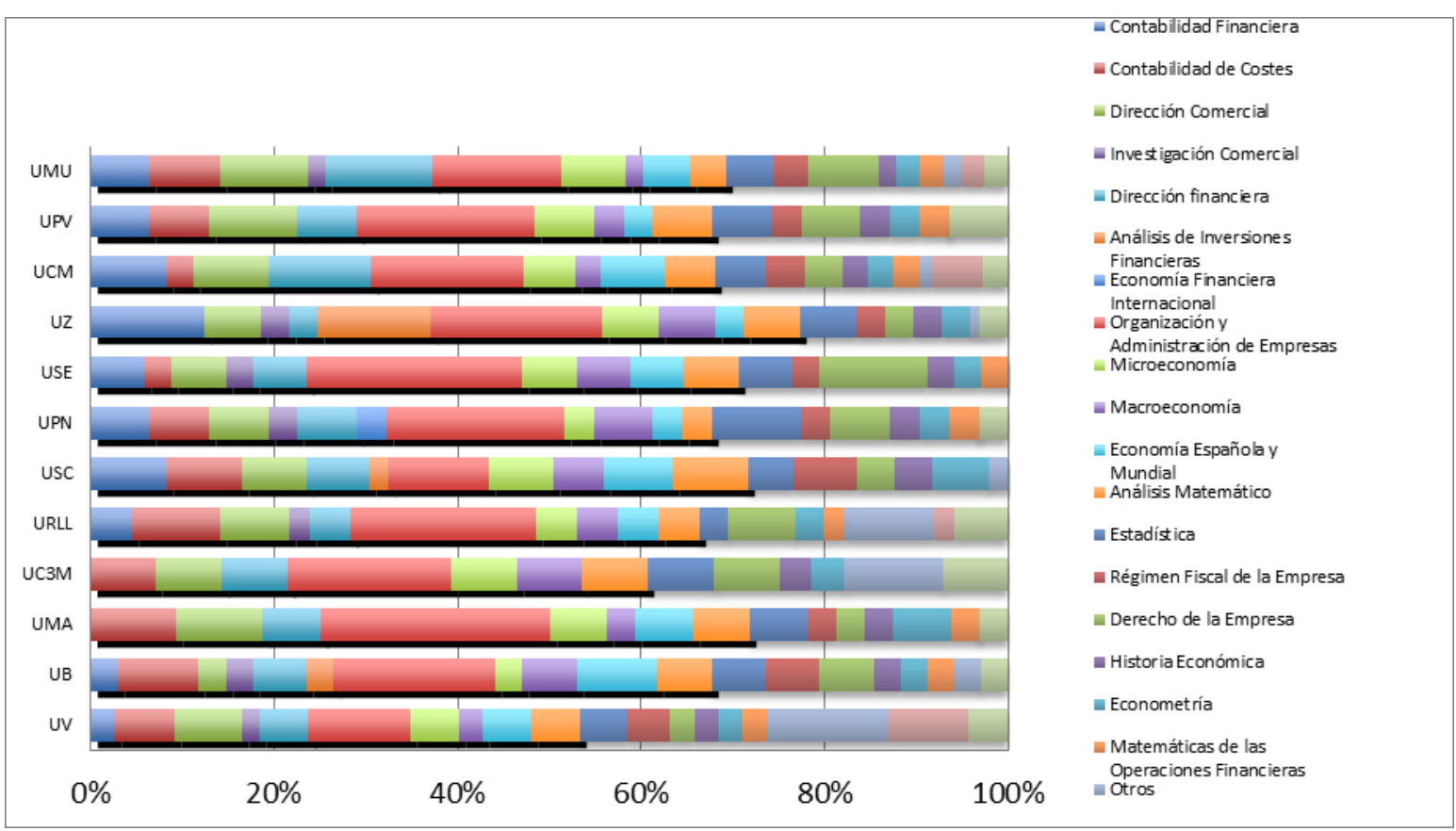

Fuente: Elaboración propia

Del análisis de ambos gráficos podemos comprobar cómo el mapa de distribución de los Conocimientos Específicos difiere entre las distintas universidades españolas analizadas, por lo que el ansiado EEES falla en nuestro país en lo que respecta a la homogeneidad de los títulos, aunque podemos afirmar que un patrón común a todos es la consolidación de los conocimientos de Organización y Administración de Empresas en las materias Obligatorias de GADE, así como la reducción de las materias vinculadas con el contexto y aquellas de corte más transversal. Pero sigue habiendo diferencias significativas en los planes de estudios, en cuanto a la carga concedida a cada contenido e, incluso, respecto a los contenidos que incluye. Vemos cómo alguno, como es el caso de la Investigación Comercial, se incorpora como Obligatorio en nuevas universidades, aunque no se generaliza a todas. Otros, como la Dirección Comercial o el Análisis de Inversiones Financieras, no siguen un patrón común; mientras que en algunos planes de estudio aumentan su carga, en otros la disminuyen.

\section{REFLEXIONES Y CONCLUSIONES}

El desarrollo de los grados, de acuerdo con el decreto de Bolonia, ha sido una oportunidad para que cada universidad adapte sus planes de estudios a las necesidades de la empresa y de la sociedad. Éstas han actuado con mayor independencia que cuando se desarrolló la anterior reforma, de manera que cada universidad ha tenido un amplio margen de actuación dentro de las directrices generales marcadas por el Ministerio. Asimismo, las Comisiones Elaboradoras de los Planes de Estudio han tenido acceso a informes desarrollados por los observatorios de empleo y por colegios profesionales que les permitía conocer los reclamos de las organizaciones empresariales.

Vemos cómo la reforma ha provocado que el título de Graduado en Administración y Dirección de Empresas concentre sus estudios de una manera más clara en las 
materias propias de la Economía de la Empresa (Organización, Marketing, Finanzas) excepto la Contabilidad, rebajando la participación de materias de contexto de la empresa (vinculadas con el conocimiento de la economía) y, también, de las materias de corte instrumental (Matemáticas, Estadística y Econometría). De forma significativa, han crecido los conocimientos en Organización y Administración de Empresas, tanto en el grupo de las materias de corte Obligatorio como en las Específicas.

Llama la atención la pérdida en el peso relativo de la Optatividad de los conocimientos en Contabilidad, lo que podría explicarse principalmente porque el nuevo Grado en Finanzas y Contabilidad (FICO) se ha generalizado en el sistema universitario español, aglutinando los estudios que se especializan en tales materias ${ }^{4} y$, por lo tanto, requiriendo de un mayor esfuerzo docente a dicha área de conocimiento. Considerando que la premisa de partida del diseño de los grados en muchas universidades españolas ha sido "coste cero", y dado que en algunos centros los recursos son ajustados, los departamentos a los que se les exige mayor presencia en esta nueva titulación podrían haber optado por disminuir su peso en GADE para poder atender las nuevas necesidades docentes.

Este argumento podría resultar contradictorio con el hecho de que algunas de las materias que han aumentado su participación en GADE también son incorporadas en nuevas titulaciones de grados especialistas vinculadas con sus áreas. Efectivamente, tal y como señalan Pérez et al. (2011), las tradicionales titulaciones de LADE y la Diplomatura en Empresariales no sólo se han transformado en GADE. Además de FICO, nos encontramos con la creación de los nuevos títulos vinculados como son el grado en Comercio, Marketing, Publicidad y Relaciones Públicas, Negocios Internacionales, Estadística y Empresa, Dirección y Creación de Empresas, etc., que cubren un importante espacio académico, científico y, sobre todo, profesional que los estudios de diplomatura y licenciatura no podían atender con la profundidad que necesitaban las empresas. No obstante, podemos justificar que la oferta global de estos grados es claramente menor que la de FICO y, por lo tanto, el consumo de recursos también lo es. Así pues, vemos como algunas de áreas de conocimiento con más implicación en estas titulaciones, como es el caso de la de marketing, han podido atender una mayor presencia en GADE a la vez que responder a estas nuevas ofertas.

Respecto a los cambios que se han producido en el paso de LADE al GADE entre las distintas universidades, apreciamos que sigue habiendo diferencias significativas en los planes de estudios en cuanto a la carga concedida a cada contenido e, incluso, respecto a los contenidos que incluye, si bien la base del cambio, dotar de mayor importancia a las materias propias de la dirección de empresas, ha sido común. Entre las diferencias que más llaman la atención distinguimos, a modo de ejemplo, que en las universidades de Zaragoza y Barcelona la importancia del área Financiera es muy destacada frente a las demás. También señalamos el crecimiento de la Investigación de Mercados en la Universidad Carlos III y la acentuada disminución de la Optatividad en las universidades de Santiago de Compostela y Murcia.

Tal vez estas diferencias pueden venir propiciadas por la libertad que ha existido en todo el proceso de diseño de los nuevos planes de estudio. El RD 1393/207 dejaba que cada universidad eligiera sus propios referentes externos que avalasen la adecuación de su propuesta a criterios nacionales o internacionales para títulos de similares características académicas. Aunque algunos documentos de referencia son comúnmente citados en las memorias de verificación consultadas (como el Libro Blanco o las recomendaciones de la Conferencia Española de Decanos de Economía

4 De las 12 universidades de nuestra muestra, 6 han incorporado a la oferta académica un grado específico en Finanzas y Contabilidad

educade, no 4, 2013, p. 72 
y Empresa), la selección de los planes de estudios de universidades españolas o europeas e internacionales de referencia no siempre ha sido la misma.

Por otra parte, el mismo decreto propone procedimientos de consulta externos, relacionados con profesionales $u$ otros colectivos. Aunque sin ánimo de ser exhaustivos, se ha hecho una revisión del apartado de consultas externas en las memorias de verificación de las universidades objeto de análisis en el presente trabajo y se observa un amplio abanico en la intensidad de uso de estos procedimientos de consulta. Podemos comprobar un continuum que va desde universidades que no indican ninguna consulta externa (salvo las necesarias exposiciones públicas) pasando por las universidades que simplemente señalan contactos con asociaciones, por aquellas que incorporan informes publicados por colegios, clubs de empresarios, 0 asociaciones de antiguos alumnos, hasta llegar en el otro extremo a las universidades que han propiciado mesas redondas, desayunos de trabajo o encuestas propias a los agentes sociales, buscando conocer de primera mano las necesidades de formación actuales en los titulados y las demandas específicas que se planteaban desde sus organizaciones. Probablemente, el plan de estudios finalmente propuesto se vea influido tanto por la selección de las entidades consultadas, cuando así ha sido hecho, como por el contenido de los informes o encuestas disponibles, que a su vez pueden estar sesgados por los propios entornos económico empresariales del lugar en el que se ubica la universidad proponente.

Hay que añadir otra razón importante que podría explicar la diferencia de las propuestas entre universidades. Tal y como señalan Pérez et al. (2011), en las universidades públicas también ha pesado el capital humano, el profesorado disponible y su especialización.

Por último, consideramos que, en muchas ocasiones, la estructura de las propias Comisiones Elaboradoras de Planes de Estudios (desigual en las universidades españolas) y, consecuentemente, el reparto de fuerzas de departamentos, puede haber propiciado algunas decisiones en la distribución final de asignaturas, con el ánimo de al menos no empeorar el status quo de las áreas de conocimiento en el plan de estudios.

Si comparamos la propuesta de GADE con las observaciones hechas por los profesionales respecto a las materias que consideran más importantes para su desarrollo laboral, observamos que, si bien las universidades han aumentado el porcentaje de conocimientos específicos relativos a Organización y Dirección de Empresas, y en conocimientos del área Financiera, ha disminuido el peso relativo de una de las áreas consideradas más importantes por los profesionales egresados, la Contabilidad. Concretamente, la disminución más destacada se ha producido en la Contabilidad de Costes.

Por otra parte consideramos que es un avance importante el incremento del peso de las Prácticas en Empresa y del Trabajo de Fin de Grado (en la mayoría de las universidades, dicho proyecto está vinculado a las prácticas realizadas). Aunque esta petición no estuviera contemplada de manera explícita en los estudios mencionados, éstos sí dejaban patente la necesidad de innovar los modelos educativos. El resultado de nuestro análisis sugiere que las universidades sí proponen nuevos modelos cuando responden a las necesidades mostradas por los empleadores de que "los estudiantes adquieran de forma directa experiencia práctica en entornos reales de trabajo, a través de estancias tuteladas en empresas, instituciones o centros de investigación" (Martínez, 2009).

Las diferencias que aún se aprecian entre GADE y las necesidades de las empresas se podrían explicar a través de varios factores: 
- Es importante el incremento de titulaciones vinculadas al área de la empresa, tal y como hemos mencionado anteriormente y que especializan al estudiante en los ámbitos de mayor empleabilidad como son las Finanzas, la Contabilidad y el Marketing. En el caso concreto de las materias de Contabilidad y Finanzas, la creciente complejidad de estas materias hace necesario contar con profesionales que tengan una formación más sólida (Arquero et al., 2010). Esto ha provocado que algunas de las principales demandas de los agentes se hayan desplazado desde GADE al nuevo grado de FICO.

- También apuntar las posibilidades de formación a través de los nuevos másteres, que podrían haber asumido parte de las necesidades expuestas por las empresas. Según los datos de Infoempleo (2011), el 33\% de las demandas de postgrados por parte de los empleadores son del ámbito empresarial, destacando los de Marketing y los de Recursos Humanos.

- Aunque a los agentes sociales (colegios de economistas, asociaciones empresariales,...) se les ha tenido en cuenta de forma mayoritaria en la elaboración de los nuevos planes, en algunos casos su participación en las comisiones de elaboración de títulos ha sido meramente testimonial, en otros han actuado como meros consultores y sólo en contadas ocasiones han participado de forma realmente activa.

- También la poco flexible estructura de personal de las universidades públicas españolas y el reparto de fuerzas entre departamento puede generar cierto sesgo en las decisiones sobre el reparto de materias en los nuevos planes de estudio de cada universidad.

En definitiva, los cambios producidos en los nuevos planes de estudio acercan en algunos aspectos los contenidos a la demanda de las empresas, básicamente en materias relacionadas con la Organización de Empresas. El hecho de que materias relativas a la Contabilidad y al Área Financiera no hayan experimentado el crecimiento deseado en GADE se explica en parte por la aparición en la mitad de las universidades analizadas del grado en FICO. Sin embargo, dado que tanto GADE como FICO no son profesiones reguladas, un graduado en alguno de estos títulos, 0 incluso en otros, como en Economía, podría ejercer la profesión de contable, auditor o asesor financiero realizando el correspondiente postgrado que le permita obtener los conocimientos necesarios o incluso, en algunos casos, obtener la titulación necesaria para ejercer profesiones regladas, como auditor o actuario.

Será objeto de estudio cuando salgan al mercado de trabajo las primeras generaciones de egresados y egresadas en GADE y FICO la comparación de las tasas de demanda por parte de las empresas, y si dichos grados se complementan 0 compiten por el mismo sector de mercado.

\section{BIBLIOGRAFÍA}

Agencia nacional de EVAluación de la Calidad y ACReditación [2005]: Libro Blanco del título de grado en economía y en empresa. Recuperado de htttp://www.aneca.es/var/media/150292/libroblanco_economia_def.pdf

ARQUERO, J.L.; DONOSO, J.A.; JIMÉNEZ, S. Y GONZÁLEZ, J.M. [2009]: Análisis exploratorio del perfil demandado para Administración y Dirección de Empresas: implicaciones para el área contable. Revista de Contabilidad, vol. 12, $\mathrm{n}^{\circ} 2$, 181-214.

ARQUERO, J.L.; JIMÉNEZ, S; GONZÁLEZ, J.M. y DONOSO, J.A. [2010]: Estudio comparativo de los nuevos grados en Finanzas y Contabilidad: especial referencia al grado de la universidad de Sevilla. Congreso ASEPUC. La Coruña 
BOE (20 de noviembre de 1990): Anexo I del Real Decreto 1421/1990. Boletín Oficial del Estado. 34350-34352.

BOE (21 de enero de 2005): Real Decreto 55/2005. Boletín Oficial del Estado. 2842-2846.

BOE (29 de octubre de 2007): Real Decreto 1393/2007. Boletín Oficial del Estado, 4403744048.

CONSEJO EUROPEO DE LISBOA: 23 y 24 de marzo de 2000. Recuperado de http://www.europarl.europa.eu/summits/lisl es.htm

EEES. DOCUMENTACIÓN BÁSICA: Recuperado de http://www.eees.es/es/documentacion

FROMENT, E. [2003]: The European Higher Education Area: a new framework for the development of higher education. Higher Education in Europe, vol. 28, n 1, 2731

FIDALGO, R. y GARCíA, J. N. [2008]: Las Directrices del Espacio Europeo de Educación Superior en el Marco Legislativo del Sistema Universitario Español. Aula Abierta, vol. 35, 35-48.

FIDALGO, R., ARIAS, O., Y GARCíA, J. N. [2007]: La eficacia diferencial de las metodologías activas a lo largo de la diplomatura de Magisterio. Documento de trabajo. Universidad de León. http://www.vem.es/myfiles/pageposts/jiu/jiu2008/

GIROTTO, M.; MUNDET, J. Y LLINÀS, X. [2013]: Estrategia y universidad: ¿̇Cuestión de calidad, gerencialismo y relaciones político-financieras? Revista de Educación, n 361. Recuperado de http://www.revistaeducacion.mec.es/doi/361_136.pdf

INFOEMPLEO. ADECO [2011]: WwW.infoempleo.es

MARÍN, S.; ANTÓN, M. Y PALACIOS, M. [2008]: El Espacio Europeo de Educación Superior: estudio empírico sobre los nuevos títulos de grado y la profesión de economista. Revista Europea de Financiación y Contabilidad, vol. 139, nº julioseptiembre, 541-587.

MARÍN, S,; ANTÓN, M. y PALACIOS, M. [2009]: An empirical study of economists and the new graduate and postgraduate economics degrees. Innovar, vol. 19, n 1, 111-129

Martínez, C.; Muñoz, I.; Peralta, M.J.; Carabias, S.; Fernandez, L. y Melara, P. [2010]: Evaluación del grado de ajuste entre el perfil competencial demandado por las empresas y el obtenido por los estudiantes de ADE. Investigaciones de Economía de la Educación, vol. 5, 245-266.

MARTíneZ, F. [2009]: La formación universitaria vs las necesidades empresariales en el marco del EEES. La cuestión Universitaria, vol. 5, 181-191.

MARTínez, F. [2011]: Los rankings de universidades: Una visión crítica. Revista de la Educación Superior, vol. XL (1), n 157, 77-97.

marzo-NAVARRo, M; Pedraja-Iglesias, M \& Rivera-Torres, P. [2009]: Curricular profile of university graduates versus business demands. Education \& Training, 51 (1), 5669.

MASFERRER, S. F. [2010]: Conocimiento y actitudes de estudiantes universitarios respecto al Espacio Europeo de Educación Superior. Revista de Formación e Innovación Educativa Universitaria, vol. 3, nº 2, 88-96.

MICHAVILA, F. [2009]: La innovación educativa. Oportunidades y barreras. ARBOR. Ciencia, Pensamiento y Cultura, vol. 185, $\mathrm{n}^{\circ}$ extra, 4-10.

mora, M., Laureano, A., Ramírez, J., y Espinosa, G. [2009]: Analysis and Design of the Representation of the Knowledge for the Implementation of a Distributed Reasoning. Revista de Matemática: Teoría y Aplicaciones, vol 16, n², 267-281

OBSERVATORIO DE INSERCIÓN PROFESIONAL Y ASESORAMIENTO LABORAL DE LA UNIVERSITAT DE VALĖNCIA (OPAL) [2011]: Segundo Estudio de las Demandas de los Empleadores de Titulados Universitarios de la Provincia de Valencia. Recuperado de http://www.fguv.org/opal/ficheros/documentos/Informe_Empleadores2_Final. pdf

Oliveros, L. [2006]: Identificación de competencias: una estrategia para la formación en el Espacio Europeo de Educación Superior. Revista Complutense de Educación, vol. 17, n¹, 101-118. 
PÉREZ, A. E IRANZO, J. [2011]: Los estudios universitarios de Economía en el ámbito del Colegio de Economistas de Madrid. Los nuevos planes de estudio y la profesión del economista. Revista de Economía 4. n 5, 3-12

PlewA, C. Y QUeSTER, P. [2008]: A dyadic study of 'Champions' in university-industry relationships, Asia Pacific Journal of Marketing and Logistics, vol. 20, n 2, 211 226.

RODRíGUEZ, R. [2009]: El reto de la convergencia europea: necesidad y cambios. Revista de Formación e Innovación Educativa Universitaria, vol. 2, n² 2, 20-30.

Tejedor, F. J. y GARCía VAlCÁrCel, A. [2007]: Causas del bajo rendimiento del estudiante universitario. Propuesta de mejora en el marco del EEES. Revista de Educación, $n^{\circ} 342,443-473$.

UNIDAD TÉCNICA DE CALIDAD - UNIVERSIDAD DE ALICANTE [2010]: Competencias y habilidades del alumnado egresado de la UA. La visión de los empleadores. Coordinadores Mateo, C y Albert M.C. Recuperado de http://utc.va.es/va/documentos/inici/informe-ocupadors.pdf.

WENDE, M. V. [2000]: The Bologna Declaration: enhancing the transparency and competitiveness on European Higher Education. Higher Education in Europe, vol. XXV, n³, 305-310. 